\title{
ДИСкУССИИ
}

DOI: https://doi.org/10.15688/jvolsu2.2020.4.13

UDC 81'42:82-1

Submitted: 30.08 .2019

LBC 81.055.1

Accepted: 28.04.2020

\section{NONDEFINITIVITY OF POETIC TEXT UNITS IN VIEW OF INTERTEXTUALITY THEORY}

\author{
Ilya V. Sergodeev \\ Snezhinsk Physics and Technology Institute \\ (branch of the National Research Nuclear University "MEPhI"), Snezhinsk, Russia
}

\begin{abstract}
The article considers the problem of finding unmarked intertextual units in fiction. The typology of intertextual relations is represented. These relations are divided into autotextuality, paratextuality, intextuality and archtextuality. Intertextual units are viewed as marked and unmarked ones. The phenomenon of intertextual crosslinking and the exchange of contexts between identical address texts units is discussed. The pattern of nondefinitivity is researched. It is divided into three subpatterns: the context type (explicit / implicit), valance, intertextual potential. A textual unit being in the implicit context has several dictionary and non-dictionary meanings at the same time. A textual unit being in the explicit context has only one dictionary meaning. Valance is discussed from the perspective of the textual aspect. The terms of polysemy and multisense are defined and differentiated. Intertextual potential bases on the examples of well-known and unknown texts, which are linked together by intertextual units. On the other hand, intertextual potential bases on the examples of references to a referent with the use of personal pronouns and common nouns, which do not nominate a person or an object. An unmarked unit of intertextuality has the following features: the implicit type of context, polysemy, intertextual potential equals to 1 . The works of R. Frost, R. Lowell, L. Hughes, W. Blake, E. E. Cummings provide practical material, which illustrates the pattern of nondefinitivity.

Key words: intertextuality, intertextual relations, type of intertextual relations, valance, implicit context, intertextual potencial, nondefinitivity, poetic text.

Citation. Sergodeev I.V. Nondefinitivity of Poetic Text Units in View of Intertextuality Theory. Vestnik Volgogradskogo gosudarstvennogo universiteta. Seriya 2. Yazykoznanie [Science Journal of Volgograd State University. Linguistics], 2020, vol. 19, no. 4, pp. 145-156. (in Russian). DOI: https://doi.org/10.15688/jvolsu2.2020.4.13
\end{abstract}

УДК 81 ' $42: 82-1$

Дата поступления статьи: 30.08.2019

ББК 81.055 .1

Дата принятия статьи: 28.04.2020

\section{НЕДЕФИНИТИВНОСТЬ ЕДИНИЦ ПОЭТИЧЕСКОГО ТЕКСТА В СВЕТЕ ТЕОРИИ ИНТЕРТЕКСТУАЛЬНОСТИ}

\section{Илья Витальевич Сергодеев}

Снежинский физико-технический институт

(филиал Национального исследовательского ядерного университета «МИФИ»), г. Снежинск, Россия

Аннотация. Статья посвящена исследованию проблемы вычленения немаркированных единиц интертекстуальности в художественном произведении. Предложена типология интертекстуальных отношений: автотекстуальность, паратекстуальность, интекстуальность, архитекстуальность. Единицы интертекстуальнос- 
ти разделены на маркированные и немаркированные. Рассматривается феномен интертекстуальной пересекаемости и обмена контекстов между идентичными единицами адресных текстов. Обсуждается признак недефинитивности текстовых единиц, который обусловлен типом контекста, значностью, интертекстуальным потенциалом. Текстовая единица, пребывающая в имплицитном контексте, определяется сразу несколькими словарными и/или несловарными значениями, а единица, пребывающая в эксплицитном контексте, определяется строго одним словарным значением. Значность описывается с позиций текстоведения: выделяются и разграничиваются понятия многозначности и многосмысленности. Интертекстуальный потенциал представлен упоминанием общеизвестных / неизвестных текстов через единицы интертекстуальности, отсылками к референту посредством личных местоимений, общеупотребительными существительными без указания имени человека или названия объекта. Установлено, что немаркированной единице интертекстуальности свойственны имплицитный контекст, многозначность, интертекстуальный потенциал, равный 1. Реализация признака недефинитивности показана на примере поэтических текстов Р. Фроста, Р. Лоуэлла, Л. Хьюза, У. Блейка, И.И. Каммингса.

Ключевые слова: интертекстуальность, интертекстуальные отношения, тип интертекстуальных отношений, значность, имплицитный контекст, интертекстуальный потенциал, недефинитивность, поэтический текст.

Цитирование. Сергодеев И. В. Недефинитивность единиц поэтического текста в свете теории интертекстуальности // Вестник Волгоградского государственного университета. Серия 2, Языкознание. - 2020. - Т. 19, № 4. - C. 145-156. - DOI: https://doi.org/10.15688/jvolsu2.2020.4.13

\section{Введение}

В языкознании существует весьма ограниченное количество подходов к решению проблемы вычленения интертекстуального (далее - ИТ) включения из общего объема рассматриваемого произведения. По мнению И.В. Арнольд, отсутствие способа вычленения ИТ включения обусловлено высокой сложностью и модальностью имплицитных функций (оценочных, характерологических, композиционных, идейных) [Арнольд, 1999]. В.Е. Чернявская пишет о коммуникативно-прагматической и психологической открытости текста адресату (предполагающей наличие интертекстуальной компетенции у читателя) [Чернявская, 2004]. С позиций когнитивного подхода ИТ включения делятся на маркированные и немаркированные [Тимофеева, 2007]. Маркированные ИТ включения выделяются авторами произведений кавычками, прописными буквами, шрифтами и пр., немаркированные - не выделяются. При всей разработанности данного подхода способ выделения немаркированных реминисценций не предлагается.

Несмотря на высокую степень проработанности теории интертекстуальности в целом, проблема вычленения немаркированных ИТ единиц все еще остается актуальной, поскольку их узнаваемость в основном зависит от фоновых знаний адресата.

\section{Материал и методы исследования}

Объектом исследования избраны немаркированные ИТ единицы. Цель статьи заключается в выявлении признаков немаркированной ИТ единицы, с тем чтобы упростить задачу выделения этой единицы из анализируемого произведения.

Методология работы строится на посвященных теории интертекстуальности трудах отечественных и зарубежных филологов (см., например: [Арнольд, 1999; Женетт, 1998; Кристева, 2004; Кузьмина, 1999; Олизько, 2009; Смирнов, 1995; Фатеева, 2000]. Основываясь на результатах исследований указанных ученых, предлагаем типологию ИТ отношений: синтагматические типы отношений авто-, паратекстуальности; парадигматические типы ин-, архитекстуальности. К автотекстуальным единицам относятся самоцитация и самоаллюзия. Паратекстуальные единицы представлены заглавием, эпиграфом, авторским комментарием, редакторской аннотацией и прочими дополнительными справочными материалами, относящимися к рассматриваемому произведению. Интекстуальная единица определяется как аллюзия, цитация, аллюзивный сюжет, аллюзивные антропонимы. Архитекстуальность понимается как жанровое подражание и как отсылка к общеизвестным художественным образам или феноменам культуры. 
И.В. Сергодеев. Недефинитивность единиц поэтического текста в свете теории интертекстуальности

Для упрощения выделения немаркированных ИТ включений из произведения, рассмотрим феномен недефинитивности текстовых единиц. Недефинитивность текстовых единиц актуализируется в случае, если реципиент работает с семантически «нелинейными» лексемами, контекстные значения которых затруднительно определить в силу их полиинтерпретативности. Недефинитивность делится на три более узких признака, выраженных в типе контекста (имплицитный vs эксплицитный контекст), значности анализируемой единицы (однозначность vs $n$-значность) и ИТ потенциале (0 vs 1$)$.

Немаркированному ИТ включению свойственен имплицитный контекст, $n$-значность, ИТ потенциал, равный 1.

Материалом исследования послужили поэтические тексты - ритмически организованная, обычно рифмованная речь, имеющая соответствующее стихам графическое выражение. В статье анализируются произведения Р. Фроста, Р. Лоуэлла, Л. Хьюза, У. Блейка, И.И. Каммингса.

\section{Результаты и обсуждение}

\section{Феномен имплицитного контекста}

Охарактеризуем эксплицитный и имплицитный типы контекста. Эксплицитный контекст - законченный отрывок письменной или устной речи (текста), пребывая в котором текстовая единица определяется строго одним словарным значением. Имплицитный контекст - законченный отрывок письменной или устной речи (текста), пребывая в котором текстовая единица не может быть определена однозначно; она полиинтерпретативна, определяется в том числе несловарными значениями.

Имплицитный контекст обусловлен пересечением кода (текстовой единицы) индивидуально-авторской картины мира с идентичными элементами адресных текстов. Текстовая единица, изначально определяемая словарным значением в заданном контексте, приобретает статус полиинтерпретативной единицы, поскольку ее смысловой комплекс актуализирует авторское, несловарное, свойственное философской системе отдельного поэта значение. Таким образом, реципиент сталки- вается с имплицитным контекстом, когда имеет дело с единицами анализа, являющимися авторскими кодами, смысл которых выходит за пределы их словарных значений. Интерпретация текстовой единицы, пребывающей в имплицитном контексте, строится на ИТ типах межтекстовых взаимодействий.

Рассмотрим имплицитный контекст на примере отрывка стихотворения Р. Фроста «Stopping by Woods» («Остановка в лесу»):

(1) Whose woods these are I think I know.

His house is in the village though;

He will not see me stopping here

To watch his woods fill up with snow.

$<\ldots>$

The woods are lovely, dark and deep,

But I have promises to keep,

And miles to go before I sleep,

And miles to go before I sleep (Frost, p. 275).

Чей это лес - я думаю, что знаю.

Его дом находится в деревне;

Он не увидит, как я останавливаюсь здесь, Чтобы посмотреть, как его лес наполняется снегом.

\section{$<\ldots>$}

Лес прекрасный, темный и глубокий, Но я должен сдержать обещания,

И пройти дальний путь, перед тем как уснуть, И пройти дальний путь, перед тем как уснуть ( здесь и далее перевод с английского наш. - И. С.).

В первой строфе представленного отрывка текстовая единица woods (лес) пребывает в эксплицитном контексте, поскольку определяется словарным значением - "an area of trees, smaller than a forest" (OLD). Однако в последней строфе произведения Р. Фрост предлагает читателю самостоятельно решить, как интерпретировать текстовую единицу woods. Автор использует стилистическую фигуру антитезы but I have promises to keep (но я должен сдержать обещания), которая приводит смысловой комплекс текстовой единицы woods в динамическое состояние, в результате чего актуализируется полиинтерпретативность этой единицы: лирический герой не хочет оставаться в лесу, так как у него есть обязательства и 
он должен пройти путь, перед тем как уснуть. В этой же строфе существительное woods coчетается с контрастирующими по смыслу эпитетами lovely (красивый), dark (темный) и deep (глубокий), что подчеркивает неоднозначность образа: с одной стороны, лес красивый и завораживающий, с другой - пугающе темный и глубокий. Семантика текстовой единицы woods обусловлена имплицитным контекстом, в котором данная единица определяется несловарными значениями. Предложим один из вариантов: лес символизирует смерть, к приходу которой лирический герой хочет подготовиться, сдержать данное им обещание, пройти жизненный путь и т. д. Таким образом, текстовая единиц woods является полиинтерпретативной единицей, поскольку аспекты ее смыслового комплекса выходят за пределы словарных значений. В имплицитном контексте пребывает также личное местоимение he (он), his (его). Он, то есть хозяин леса из первой строфы, семантически преобразуется в некое сверхъестественное существо, управляющее лесом (смертью) из последней строфы. Другими словами, вариант интерпретации he напрямую зависит от контекстного значения woods.

Рассмотрим текстовую единицу woods c позиций ИТ отношений с тем, чтобы уточнить варианты ее контекстных значений. Идентичная единица $\operatorname{wood}(s)$ встречается 121 раз в текстовом корпусе поэта, представленном в книге «Complete Poems of Robert Frost» (1964).

Автотекстуальные связи идентичных единиц woods формируют общий интерконтекст, в рамках которого эти единицы обмениваются своими контекстными значениями, что приводит к динамике смыслового комплекса каждой из них. Рассмотрим несколько примеров.

В стихотворении «The Demiurge's Laugh» («Смех демиурга») встречаем поэтический образ wood, идентичный описанному выше:

(2) It was far in the sameness of the wood;

I was running with joy on the Demon's trail,

Though I knew what I hunted was no true god (Frost, p. 35).

Это было далеко в единообразии леса; Я радостно бежал по следу Демона,

Хотя я знал, что искомое мною не было истинным Богом.
С одной стороны, wood может обозначать обыкновенный лес-место действия стихотворения. С другой стороны, в связке с существительным sameness (единообразие) текстовая единица wood представляется метафорическим лесом заблуждений, то есть множеством одинаково неверных суждений. К выбору такого варианта контекстного значения подталкивает также строка I knew what I hunted was no true god (я знал, что охотился не на истинного Бога), которую можно перефразировать так: я никогда не искал правды; то, что я искал, не было правдой. Странствие по «лесу заблуждений» является аллюзивным сюжетом, отсылающим к «Божественной комедии» Д. Алигьери: Земную жизнь пройдя до половины, / Я очутился в сумрачном лесу (Данте, с. 18). По мнению М.Л. Лозинского, переводчика и исследователя творчества Д. Алигьери, строку Я очутился в сумрачном лесу следует понимать так: очутился «в темных дебрях грехов и заблуждений». Комментатор также приводит в пример параллельное место из трактата Д. Алигьери «Пир», в котором встречается фраза порочный лес этой жизни [Лозинский, 2017, с. 307].

Другим произведением Р. Фроста, в котором находим идентичный образ, эксплицируемый существительным wood, пребывающим в имплицитном контексте, является стихотворение «The Road Not Taken» («Непройденная дорога»):

(3) Two roads diverged in a yellow wood, And sorry I could not travel both... (Frost, p. 131).

Две тропы разошлись в желтом лесу, Увы, я не могу пройти обе...

Р. Фрост посвятил это стихотворение своему англо-уэльскому другу - поэту Э. Томасу. Он хотел с иронией описать постоянные сомнения Э. Томаса в правильности выбора жизненного пути и, как следствие, переживания из-за упущенных возможностей. Автор иронично комментировал эту ситуацию так: «No matter which road you take, you'll always sigh and wish you'd taken another» (Frost) «Неважно, какую дорогу ты выберешь. В любом случае ты будешь жалеть, что не избрал другую». 
И.В. Сергодеев. Недефинитивность единиц поэтического текста в свете теории интертекстуальности

В представленном отрывке (3) герой выбирает, по какой из двух дорог ему следовать дальше. Дороги являются аллегорией вариантов жизненного пути, а лес - аллегорией самой жизни. В поэтическом тексте актуализировано несловарное значение «лес жизнь», что свидетельствует об имплицитном контексте употребления рассматриваемой единицы.

В имплицитном контексте пребывает существительное woods и в стихотворении «Desert Places» («Пустынные места»):

(4) The woods around it have it - it is theirs.

All animals are smothered in their lairs.

I am too absent-spirited to count;

The loneliness includes me unawares.

$<\ldots>$

They cannot scare me with their empty spaces

Between stars - on stars where no human race is.

I have it in me so much nearer home

To scare myself with my own desert places (Frost, p. 386).

Леса, окружающий поле, хранят его. Оно-их.

Все животные затаились в своих норах.

Я слишком растерян, чтобы это имело значение:

Одиночество застало меня врасплох.

$<\ldots>$

Они не напугают меня

своими пустыми местами

Между звездами - звездами, где нет людей.

Этого во мне все больше, чем я ближе к дому.

Оно пугает меня собственными

пустынными местами.

Процитированное стихотворение- об одиночестве. Пустота заснеженного леса сравнивается Р. Фростом с внутренней пустотой лирического героя. Обратим внимание на параллелизм the woods have it (леса хранят его) и I have it in me (оно во мне), объединяющий образы woods и героя произведения. Строгая рифма empty spaces (пустые места) - desert places (пустынные места) фонетически подчеркивает связь бескрайнего снежного леса и внутреннего состояния лирического героя. Словосочетание their empty spaces (их пустые места) относится именно к существительному woods, так как оба личных местоиме- ния they (они) и their (их) первой строки последней строфы рассматриваемого поэтического текста стоят во множественном числе. Во всем стихотворении во множественном числе употреблены только три существительных woods (леса), animals (звери) и lairs (норы). Звери, спрятавшиеся в норы, упоминаются только раз как элемент пейзажа, подчеркивающий пустоту леса и одиночество лирического героя, поэтому вряд ли Р. Фрост обращается к ним вновь посредством личного местоимения в конце стихотворения. Следовательно, местоимения they и their относятся к центральному образу рассматриваемого произведения, эксплицированному существительным woods. Соотнося местоимение they с существительным woods, можно интерпретировать первые строки последней строфы стихотворения (They cannot scare me with their empty spaces / Between stars - on stars where no human race is) следующим образом: вершины лесных деревьев достают до звезд, однако звезды безлюдны, поэтому данная связь только усиливает гнетущее состояние лирического героя. Основываясь на приведенных аргументах, делаем вывод, что существительное woods в «Desert Places» пребывает в имплицитном контексте, поскольку может быть определено по крайней мере одним несловарным значением: «лес - одиночество».

Таким образом, рассмотренная единица woods как элемент индивидуально-авторской картины мира Р. Фроста и немаркированная единица автотекстуальных отношений может быть интерпретирована следующим образом: «лес - смерть - заблуждения - жизненный путь - одиночество».

Четыре рассмотренных текстовых фрагмента из произведений Р. Фроста «Stopping by Woods», «The Demiurge's Laugh», «The Road Not Taken» и «Desert Places» содержат примеры имплицитного контекста. Различия между имплицитным и эксплицитным типами контекста заключаются в том, что текстовая единица, пребывающая в имплицитном контексте, определяется несколькими несловарными значениями, возникающими благодаря ИТ связям между элементами индивидуально-авторской картины мира и идентичными элементами адресных текстов. Если текстовая единица пребывает в эксплицитном кон- 
тексте, она определяется строго одним из своих словарных значений.

\section{Значность единиц поэтического текста}

Значность текстовых единиц можно выразить через дизьюнкцию «однозначность vs $n$-значность». Под однозначными текстовыми единицами понимаются единицы, которые определяются строго одним словарным значением в заданном эксплицитном контексте, $n$-значные единицы пребывают в имплицитном контексте и определяются сразу несколькими словарными и/или несловарными значениями. Если текстовая единица $n$-значна, ее следует считать ИТ единицей. Рассмотрим отрывок стихотворения Р. Лоуэлла «For the Union Dead» («Единой смерти»).

(5) The stone statues of the abstract Union Soldier grow slimmer and younger each yearwasp-waisted, they doze over muskets and muse through their sideburns.

Shaw's father wanted no monument except the ditch, where his son's body was thrown and lost with his "niggers" (Lowell).

Каменные памятники абстрактного солдата Союза становятся стройнее и моложе с каждым годом у них осиная талия, они дремлют над мушкетами и размышляют через свои бакенбарды...

Отец Шоу не хотел памятника -

только канаву,

куда бросили тело его сына

и оставили с его «нигерами».

Выделенная текстовая единица the abstract Union Soldier (абстрактный солдат Союза) выражает собирательный образ солдат, погибших во время Гражданской войны в США (1861-1865). Олицетворение grow slimmer and younger (становятся стройнее и моложе) пребывает в имплицитном контексте, поскольку неясно, каким образом каменные памятники могут становиться моложе. Следующая строфа начинается текстовой единицей Shaw (Шоу) - аллюзивным антропонимом, отсылающим к знаменитому полковнику армии Союза в период Гражданской войны в США
Р.Г. Шоу, который принял командование первым чернокожим полком (54-й Массачусетский) и героически погиб (Fordham Preparatory School). В стихотворении Р. Лоуэлл выражает свое разочарование в войне. По мнению поэта, кровопролитие не способно сделать людей лучше или уравнять их права:

(6) The ditch is nearer.

There are no statues for the last war here; on Boylston Street, a commercial photograph shows Hiroshima boiling

over a Mosler Safe, the "Rock of Ages" that survived the blast. Space is nearer. When I crouch to my television set, the drained faces of Negro school-children rise like balloons (Lowell).

Канава ближе.

Здесь нет памятников последней войны; на Бойлстон-стрит фотограф-коммерсант показывает, как Хиросима кипит

над Мослер Сейф, «Твердыня Вечная», которая пережила взрыв. Космос ближе. Когда я припадаю к экрану своего телевизора, истощенные лица негров-школьников взлетают, словно шарики.

В первой строфе представленного отрывка из «For the Union Dead» автор подчеркивает, что у солдат «последней войны» (имеются в виду бомбардировки Хиросимы) нет и не может быть памятника, поскольку никто не в силах пережить удар ядерного оружия. Сравнение the drained faces of Negro school-children rise like balloons (истощенные лица негров-школьников взлетают, словно шарики) показывает, что на момент создания стихотворения права афроамериканцев все еще не были равны правам белых людей. Отметим, что рассматриваемый текст был написан в 1960 г., когда в США остро стоял вопрос расовой дискриминации. В то время наблюдалось массовое общественное движение чернокожих граждан США (Civil Rights Movement).

Возвращаясь к анализируемой текстовой единице the abstract Union Soldier, можно сказать, что, с одной стороны, она является аллюзией и отсылает к личности полковника Р.Г. Шоу. Об этом свидетельствует упомяну- 
И.В. Сергодеев. Недефинитивность единиц поэтического текста в свете теории интертекстуальности

тое выше олицетворение grow younger (становятся моложе): полковник Р.Г. Шоу погиб в возрасте двадцати пяти лет. С другой стороны, в рамках стихотворения «For the Union Dead» она может быть интерпретирована как символ войны, страданий и убийств. В одном поэтическом образе наблюдаются сразу несколько различных значений:

1. Неизвестный солдат как собирательный образ всех погибших героев войны.

2. «Абстрактный» солдат как противопоставление реальным героям, имена которых преданы забвению по тем или иным причинам. В данном случае «абстрактный» солдат противопоставляется полковнику Р.Г. Шоу, чей памятник, согласно «For the Union Dead», - канава, куда он был брошен после смерти вместе со своими чернокожими друзьями.

3. Памятник неизвестному солдату как символ убийств и смерти.

Текстовая единица the abstract Union Soldier является $n$-значной, а именно - трехзначной. Зависимость значности от контекста - основополагающий фактор интертекстуальности рассматриваемой единицы. Имплицитный контекст обеспечивает семантическую нелинейность текстового фрагмента, которая выражается в ИТ связях исследуемых текстовых единиц с адресными текстами. В результате актуализируется многозначность, а точнее многосмысленность (способность текстовой единицы определиться сразу несколькими, в том числе несловарными, значениями в рамках одного контекста), единицы поэтического текста. Так, the abstract Union Soldier в «For the Union Dead» выражает собирательный общекультурный образ и, одновременно с этим, является немаркированной единицей архитекстуальности, отсылающей реципиента к исторической личности полковника Р.Г. Шоу и событиям, связанным с его гибелью.

\section{Интертекстуальный потенциал текстовых единиц}

ИТ потенциал - один из основных признаков ИТ единицы, который обеспечивает динамику ее смыслового комплекса. Под ИТ потенциалом понимается совокупность всех возможных ИТ связей между анализируемой единицей базового произведения и идентичными ей единицами адресных текстов. Реципиент способен частично декодировать эти связи. Результат расшифровки ИТ единиц зависит от широты фоновых знаний и развитости компетенций читателя. Любой из предложенных вариантов интерпретации не будет исчерпывающим, поскольку непрерывно создаются новые тексты (а значит, новые ИТ связи).

Представим текстовые единицы дизъюнкцией 0 vs 1 , где 0 - отсутствие; 1 - наличие ИТ потенциала. Текстовые единицы, ИТ потенциал которых равен 1 , можно разделить на два типа: а) упоминание или цитирование общеизвестных / неизвестных текстов через единицы авто-, пара-, ин-, архитекстуальности; б) отсылки к референту через личные местоимения либо общеупотребительные существительные без указания имени человека или названия объекта.

Рассмотрим первый тип (упоминание или цитирование общеизвестных / неизвестных текстов) текстовой единицы, обладающей ИТ потенциалом, на примере отрывка из стихотворения американского поэта Л. Хьюза «The Negro Speaks of Rivers» («Черный говорит о реках»).

(7) I've known rivers:

I've known rivers ancient as the world and older than the flow of human blood in human veins.

My soul has grown deep like the rivers (Hughes).

Я узнал реки:

Я узнал реки, древние как мир

и старше, чем течение человеческой крови в человеческих венах.

Моя душа проросла вглубь, как реки.

ИТ потенциал выделенной текстовой единицы равен 1 , так как поэтический образ, выраженный существительным rivers (реки), является отсылкой к общеизвестному символу «река - реки». В статье «River» в «Peter Greif's SYMBOLARIUM» (Энциклопедия знаков и символов), приводятся следующие толкования обсуждаемого символа: «мировой поток явлений, течение жизни; символ уходящего времени и жизни; река жизни - царство 
божества, макрокосм; река смерти - явное существование, мир изменений, микрокосм; устье реки сходно по символике с воротами (дверью); река - проводник в иное царство, в океан единства» (Энциклопедия знаков и символов). В широком смысле понимание рассматриваемого символа rivers (реки) сводится к идеям древнегреческого философа Гераклита Эфесского, согласно которым любая река есть символ времени и необратимых процессов: «Все течет, все меняется»; «Все течет, и ничто не остается на месте» (Серов). Текстовая единица rivers (реки) обладает мощным ИТ потенциалом, поскольку является ИТ ссылкой сразу к большому количеству адресных текстов. Таким образом, текстовая единица rivers (реки) - это реминисценция к культурологическим, философским, мифологическим текстам, а также интекстуальная аллюзия на существующие или вымышленные реки: Нил, Евфрат, Лету, Стикс и т. д.

Представленная текстовая единица rivers (реки) выступает широким общеизвестным мифологическим символом, поэтому ее ИТ потенциал равен 1. Рассмотрим малоизвестную, узконаправленную реминисценцию на примере отрывка из «The Mental Traveller» («Странник духа») английского поэта У. Блейка:

(8) I traveld thro' a Land of Men

A Land of Men \& Women too

And heard \& saw such dreadful things

As cold Earth wanderers never knew... (Blake, p. 499).

Я шел через Страну Мужей.

Страну Мужей и Жен.

И слышал, и видел такие ужасные вещи,

Которые никогда не знали странники холодной Земли...

Из контекста рассматриваемого отрывка видно, что образ природного мира, представленный единицей cold Earth wanderers (странники холодной Земли), не тождественен миру $A$ Land of Men \& Women (страна Мyжей и Жен).

Смысловой комплекс текстовой единицы dreadful things (ужасные вещи) раскрывается через проспекцию. В ходе прочтения этого стихотворения возможно сформировать базовое контекстное значение данной единицы анализа:
(9) ...And if the Babe is born a Boy

He's given to a Woman Old...

$<\ldots>$

...She lives upon his shrieks and cries,

And she grows young as he grows old... (Blake, p. 500).

...И если рождается мальчик,

Его отдают Старухе...

$<\ldots>$

...Она живет его криками и плачем,

И она молодеет, когда он старится...

Из данного отрывка видно, что «ужасным» У. Блейк называет непонятный и неприемлемый для природного мира закон, который справедлив в стране Мужей и Жен. Этот закон выражен обобщением dreadful things, pacкрывающимся в образе старухи, которая молодеет за счет того, что старится новорожденный мальчик.

A Land of Men \& Women является единственной из выделенных текстовых единиц, смысловой комплекс которой не может быть однозначно интерпретирован. Текстовые единицы dreadful things и cold Earth wanderers, напротив, определяются однозначными контекстными значениями через описанные выше сравнение и проспекцию.

Для интерпретации смыслового комплекса единицы $A$ Land of Men \& Women необходимо обратиться к адресным текстам (преимущественно другим произведениям У. Блейка). A Land of Men \& Women является самоаллюзией на четверичную мифологическую систему поэта, согласно которой Вселенная проходит следующие духовные состояния: Eden (Рай) - единство Творца и его творения; Generation (Порождение) - отделение человека от Бога, человека от других людей; Beulah (Беула) - христианский идеал, восстановление единства человека с Божеством; Ulro (Ульро) - материальный мир, Ад [Зверев, 1982]. Иерархически указанные состояния располагаются следующим образом (от высшего к низшему): Eden - Beulah Generation - Ulro. Принимая данную систему во внимание, будем понимать под текстовой единицей cold EARTH wanderers - «cold 
И.В. Сергодеев. Недефинитивность единиц поэтического текста в свете теории интертекстуальности

ULRO wanderers», то есть странники материального мира.

В пророческих книгах У. Блейка «Vala, or The Four Zoas» («Вала, или Четыре Зоа») и «Jerusalem» («Иерусалим») описывается духовное состояние, обозначенное как Generation. Некоторые из примеров:

(10) ...The Generation of Decay \& Death \& his Regeneration by the Resurrection from the dead... (Blake, p. 274).

...Порождение Разложения и Смерти и его Регенерации через Воскрешение из мертвых...

(11) ...Generating Love: a pretence of love to destroy love... (Blake, p. 667).

...Любовь Порождения: предлог любви уничтожить любовь...

Основной отличительной чертой духовного состояния Generation является бинарность - вечное возрождение одного начала посредством уничтожения другого и наоборот. A Land of Men \& Women - самоаллюзия на образ мира, пребывающего в состоянии Generation. В произведении «The Mental Traveller» наблюдается противопоставление мужского и женского начал - бинарная основа Generation. В рамках анализируемого поэтического текста мужское начало возрождается посредством женского, и наоборот, то есть $A$ Land of Men \& Women выступает частным случаем Generation.

Обратимся к вариантам интерпретации единицы $A$ Land of Men \& Women, предложенным другими исследователями. У.М. Росетти истолковывает рассматриваемую единицу как противостояние старого и нового взаимоотношение идей в контексте постоянно меняющихся культурологических и социологических реалий (комментарий У.М. Росетти приводится по: [Hirsch, 1964]). У.Б. Йейтс считает, что идеология и философия $A$ Land of Men \& Women навеяна идеями теософа Э. Сведенборга (1688-1772) и представляет собой принцип отделения каждого от своей противоположности, разделения и самопоглощения [Yeats, 2008]. По мнению К. Рейн, прообразом $A$ Land of Men \& Women является притча Платона из диалога «Политик» (в Зо- лотом Веке мужчины росли от старости к младенчеству, так же как и Младенец У. Блейка) [Raine, 1985]. Е.В. Витковский считает, что текстовая единица $A$ Land of Men \& Women «вскрывает извращенность отношений в современном Блейку обществе» [Витковский, 1975, с. 607]. А.М. Зверев видит в $A$ Land of Men \& Women «аллегорию, изображающую тернистый и причудливый путь Свободы через века истории» [Зверев, 1982]. А.В. Глебовская сравнивает $A$ Land of Men \& Women с обобщением духовного опыта автора и всего человечества [Глебовская, 2006].

Таким образом, вариативность контекстных значений, а также нелинейные ИТ связи между базовой единицей анализа и идентичными ей единицами адресных текстов свидетельствуют о том, что ее ИТ потенциал равен 1.

Проиллюстрируем второй тип (отсылки к референту через личные местоимения или общеупотребительные существительные) текстовых единиц, обладающих ИТ потенциалом, отрывком из стихотворения «You shall above all things be glad and young» («Прежде всего радуйся и будь молодым») американского поэта И.И. Каммингса.

(12) you shall above all things be glad and young For if you're young, whatever life you wear

it will become you; and if you are glad whatever's living will yourself become(Cummings).

Прежде всего радуйся и будь молодым, Поскольку, если ты молод, какую бы жизнь ты не носил,

она станет тобой; и если ты радуешься, любая жизнь станет как ты.

Выделенная текстовая единица, представленная личным местоимением уои (ты), относится к ИТ единицам, связи между которыми априори множественны и нелинейны, так как референт ни обозначен антропонимом или существительным, ни дополнен эпитетом или другими средствами выражения. Количество контекстных значений единицы уои (ты) начинается с двух: уои (ты) - тот, кто читает данное произведение; уои (ты) - конкретный человек, к которому обращается И.И. Кам- 
мингс, но не называет его. Интерпретируя общеупотребительные ИТ единицы, реципиент встраивается в творческий процесс мыслительной деятельности автора, в ходе которого называются очевидные для автора, но неявные для читателя объекты. Перед реципиентом открывается семиотическое поле нелинейно связанных между собой идентичных текстовых единиц, чей ИТ потенциал стремится к бесконечности.

Значность ИТ единицы обнаруживается при помещении ее в имплицитный контекст, позволяющий говорить о неустойчивости смыслового комплекса этой единицы. Другими словами, любая ИТ единица, встречающаяся в имплицитном контексте, по своей природе $n$-значна, так как ее смысловой комплекс включает совокупность базового контекстного значения и контекстных значений идентичных ИТ единиц, содержащихся в адресных текстах. ИТ потенциал выражает вариативность контекстных значений идентичных ИТ единиц, которые гипотетически могут быть декодированы реципиентом.

\section{Выводы}

Недефинитивность является базовым признаком немаркированной ИТ единицы, который актуализируется благодаря полиинтерпретативности этой единицы. Невозможность или неспособность реципиента вычленять немаркированные единицы из текста приводит к смысловой размытости, непониманию сути произведения. Однако это «непонимание» может служить инструментом выделения немаркированных ИТ единиц. В этом случае процесс интерпретации идет не от читателя к тексту, а от текста к читателю. Реципиент рассматривает совокупность параметров смысловой неопределенности текстовой единицы, которая выражена в признаке недефинитивности. К этим параметрам относятся: тип контекста, значность и ИТ потенциал. Если рассматриваемая текстовая единица пребывает в имплицитном контексте, многозначна и обладает ИТ потенциалом, равным 1 , то ее можно считать ИТ единицей.

Текстовая единица произведения, отвечающая предложенным параметрам, вступает в ИТ отношения с идентичной ей единицей адресных текстов, в результате чего реализуется обмен контекстами между этими единицами. Именно этот обмен делает базовую текстовую единицу недефинитивной, то есть способной определяться сразу несколькими, в том числе несловарными, значениями в рамках одного заданного контекста. Так, рассмотренная выше единица woods в «Stopping by Woods» P. Фроста вступает в автотекстуальную связь с идентичными единицами woods других произведений поэта, в связи с чем ее смысловой комплекс расширяется до семантического ряда, представленного несловарными значениями: «лес - смерть - заблуждения - жизненный путь - одиночество». Единица the abstract Union Soldier из «For the Union Dead» Р. Лоуэлла в силу ее архитекстуальной природы интерпретируется как собирательный образ героя войны, жертв войны и историческая личность - полковник Р. Г. Шоу. Номинация the Land of Men \& Women в «The Mental Traveller» У. Блейка эксплицирует в его мифологии сложный поэтический образ, являющийся самоаллюзией на бинарный образ, обозначенный как Generation, аллюзией на труды Э. Сведенборга и притчу из диалога «Политик» Платона.

Опора на признак недефинитивности единиц поэтического текста способна облегчить процесс интерпретации ИТ включений в общем текстовом объеме рассматриваемого произведения.

\section{СПИСОК ЛИТЕРАТУРЫ}

Арнольд И. В., 1999. Семантика. Стилистика. Интертекстуальность. СПб. : Изд-во С.-Петерб. ун-та. 448 с.

Витковский Е., 1975. Примечания // Поэзия английского романтизма XIX века. М. : Худож. лит. C. 599-656.

Глебовская А. В., 2006. Предварение. Комментарии // Блейк У. Песни Невинности и Опыта. СПб. : Азбука-классика. С. 5-21, 223-259.

Женетт Ж., 1998. Фигуры : в 2 т. М. : Изд-во им. Сабашниковых. Т. 1. 470 с.; Т. 2.469 с.

Зверев А. М., 1982. Комментарии // Блейк У. Стихи : сборник : на англ. и рус. яз. / сост. А. М. Зверев. M. :Прогресc. С. 499-555. URL: https://imwerden. de/pdf/blake_selected_verse_stikhi_1982_text.pdf.

Кристева Ю., 2004. Избранные труды: разрушение поэтики. М. : РОССПЭН. 656 c. 
Кузьмина Н. А., 1999. Интертекст и его роль в процессах эволюции поэтического языка. Екатеринбург : Изд-во Урал. ун-та ; Омск : Омск. гос. ун-т. $268 \mathrm{c}$.

Лозинский М. Л., 2017. Комментарий // Алигьере Д. Божественная комедия : С иллюстрациями Гюстава Доре / пер. с итал. М. Л. Лозинского. М. : Времена : АСТ. С. 305-428.

Олизько Н. С., 2009. Интердискурсивность постмодернистского письма (на материале творчества Дж. Барта). Челябинск : Фотохудожник. $162 \mathrm{c}$.

Смирнов И. П., 1995. Порождение интертекста. Элементы интертекстуального анализа с примерами из творчества Б. Пастернака. СПб. : СПбГУ. 189 с.

Тимофеева Т. Н., 2007. Специфика прецедентных феноменов в англоязычных научных текстах экономической тематики // Вопросы когнитивной лингвистики. № 2 (11). С. 69-73.

Фатеева Н. А., 2000. Контрапункт интертекстуальности, или Интертекст в мире текстов. М. : Агар. 280 c.

Чернявская В. Е., 2004. Интертекст и интердискурс как реализация текстовой открытости // Вопросы когнитивной лингвистики. № 1 (001). С. 106-111.

Hirsch E. D., 1964. Innocence and Experience: Introduction to Blake. New Heaven : Yale University Press. 350 p.

Raine K., 1985. Defending Ancient Springs: Essays. Great Barrington : Lindisfarne Press. 198 p.

Yeats W. B., 2008. The Collected Works of W.B. Yeats. Vol. XIII. A Vision. The Original 1925 Version. Charleston : BiblioLife. 340 p.

\section{ИСТОЧНИКИ И СЛОВАРИ}

Данте - Алигьере Д. Божественная комедия : С иллюстрациями Гюстава Доре / пер. с итал. М. Л. Лозинского. М. : Времена : АСТ. 432 с.

Серов - Серов В. Энциклопедический словарь крылатых слов и выражений. 2019. URL: https:// roya $11 \mathrm{ib}$.com/read/s erov_vadim/ entsiklopedicheskiy_slovar_krilatih_slov_i virageniy.html (дата обращения: 29.08. 2019).

Эничклопедия знаков и символов - Река // Энциклопедия знаков и символов. 2019. URL: http:// www.symbolarium.ru/index.php/Река (дата обращения: 29.08.2019).

Blake - Blake W. The Complete Poems. L. : Penguin Group, 2004. 1071 p.

Cummings - Cummings E. E. The Gladdest Thing. 2019. URL: https://gladdestthing.com/poems/ you-shall-above-all-things-be-glad-and-young (date of access: 29.08.2019).
Fordham Preparatory School - Col. Robert Gould Shaw, ex-1854 // Fordham Preparatory School. 2019. URL: https://www.fordhamprep.org/page.cfm?p=4856 (date of access: 29.08.2019).

Frost - Frost R. Complete Poems of Robert Frost. N.Y. : Holt, Rinehart \& Winston, 1964. 666 p.

Hughes - Hughes L. The Negro Speaks of Rivers. 1994. URL: https://poets.org/poem/negrospeaks-rivers (date of access: 29.08.2019).

Lowell - Lowell R. For the Union Dead. 2003. URL: https://www.poetryfoundation.org/poems/ 57035/for-the-union-dead (date of access: 29.08.2019).

OLD - Wood // Oxford Learners Dictionaries. 2019. URL: https:/www.oxfordlearnersdictionaries.com/ definition/english/wood?q=woods (date of access: 29.08.2019).

\section{REFERENCES}

Arnold I.V., 1999. Semantika. Stilistika. Intertekstualnost [Semantics. Stylistics, Intertextuality]. Saint Petersburg, Izd-vo SanktPeterburgskogo universiteta. $448 \mathrm{p}$.

Vitkovskiy E., 1975. Primechaniya [Notes]. Poeziya angliyskogo Romantizma XIX veka [Poetry of English Romanticism of the $19^{\text {th }}$ c.]. Moscow, Khudozhestvennaya literatura Publ., pp. 599-656.

Glebovskaya A.V., 2006. Predvarenie. Kommentarii [Prediction. Comments]. Blake W. Pesni Nevinnostii Opyta [Songs of Innocence and of Experience]. Saint Petersburg, Azbuka-klassika Publ., pp. 5-21, 223-259.

Zhenett Zh., 1998. Figury: $v 2 t$. [Figures. In 2 Vols.]. Moscow, Izd-vo im. Sabashnikovykh, vol. 1. 470 p., vol. 2. 469 p.

Zverev A.M., 1982. Kommentarii [Comments]. Stikhi: sbornik: na angl. i rus. yaz. [Poems. Collection. In English and Russian]. Moscow, Progress Publ.,pp. 499-555. URL: https://imwerden.de/pdf/ blake_selected_verse_stikhi_1982_text.pdf.

Kristeva Yu., 2004. Izbrannye trudy: razrushenie poetiki [Chosen Works. Destruction of Poetics]. Moscow, ROSSPEN Publ. $656 \mathrm{p}$.

Kuzmina N.A., 1999. Intertekst i ego rol v protsessakh evolyutsii poeticheskogo yazyka [Intertext and Its Role in Poetic Languages Evolution Processes]. Yekaterinburg, Izd-vo Uralskogo universiteta; Omsk, Omskiy gosudarstvennyy universitet. $268 \mathrm{p}$.

Lozinskiy M.L., 2017. Kommentariy[Note]. Alighieri D. Bozhestvennaya komediya: S illyustratsiyami Gyustava Dore [The Divine Comedy. With Illustrations by Gustave Dore]. Moscow, Vremena Publ., AST Publ., pp. 305-428. 
Olizko N.S., 2009. Interdiskursivnost postmodernistskogo pisma (na material tvorchestva Dzh. Barta) [Interdiscoursivity of Postmodern Letter (Exemplified By J. Barths Works)]. Chelyabinsk, Fotokhudozhnik Publ. 162 p.

Smirnov I.P., 1995. Porozhdenie interteksta. Elementy intertekstualnogo analiza s primerami iz tvorchestva B. Pasternaka [Generation of Intertext. Elements of Intertextual Analysis with Examples from B. Pasternak's Works]. Saint Petersburg, SPBGU. 189 p.

Timofeeva T.N., 2007. Spetsifika pretsedentnykh fenomenov $\mathrm{v}$ angloyazychnykh nauchnykh tekstakh ekonomicheskoy tematiki [Specifity of Precedent Phenomena in English Scientific Texts on Economy]. Voprosy kognitivnoy lingvistiki [Issues of Cognitive Linguistics], no. 2 (11), pp. 69-73.

Fateeva N.A., 2000. Kontrapunkt intertekstualnosti, ili Intertekst $v$ mire tekstov [Counterpoint of Intertextuality, or Intertext in the World of Texts]. Moscow, Agar Publ. 280 p.

Chernyavskaya V.E., 2004. Intertekst i interdiskurs kak realizatsiya tekstovoy otkrytosti [Intertext and Interdiscourse as a Realization of Text Semantic Openness]. Voprosy kognitivnoy lingvistiki [Issues of Cognitive Linguistics], no. 1, pp. 106111.

Hirsch E.D., 1964. Innocence and Experience: Introduction to Blake. New Heaven, Yale University Press. $350 \mathrm{p}$.

Raine K., 1985. Defending Ancient Springs: Essays. Great Barrington, Lindisfarne Press. 198 p.

Yeats W.B., 2008. The Collected Works of W.B. Yeats. Vol. XIII: A Vision: The Original 1925 Version. Charleston, BiblioLife. 340 p.

\section{SOURCES AND DICTIONARIES}

Alighieri D. Bozhestvennaya komediya: S illyustratsiyami Gyustava Dore [The Divine Comedy. With Illustrations by Gustave Dore]. Moscow, Vremena Publ., AST Publ. 432 p.

Serov V. Entsiklopedicheskiy slovar krylatykh slov $i$ vyrazheniy [Encyclopedic Dictionary of Proverbial Expressions]. 2019. URL: https:// royallib.com/read/s erov_vadim/ entsiklopedicheskiy_slovar_krilatih_slov_i virageniy.html (accessed 29 August 2019).

Entsiklopediya znakov $i$ simvolov [Encyclopedia of Signs and Symbols]. URL: http://www.symbolarium. ru/ index.php/Reka (accessed 29 August 2019).

Blake W. The Complete Poems. London, Penguin Group, 2004. 1071 p.

Cummings E.E. The Gladdest Thing. 2019. URL: https:// gladdestthing.com/poems/you-shall-above-allthings-be-glad-and-young (accessed 29 August 2019).

Col. Robert Gould Shaw, ex-1854. Fordham Preparatory School. 2019. URL: https:// www. fordhamprep. org/page.cfm? $\mathrm{p}=4856$ (accessed 29 August 2019).

Frost R. Complete Poems of Robert Frost. New York, Holt, Rinehart \& Winston, 1964. 666 p.

Hughes L. The Negro Speaks of Rivers. 1994. URL: https://poets.org/poem/negro-speaks-rivers (accessed 29 August 2019).

Lowell R. For the Union Dead. 2003. URL: https:// www.poetryfoundation.org/poems/57035/forthe-union-dead (accessed 29 August 2019).

Wood.Oxford Learners Dictionaries. 2019. URL: https://www.oxfordlearnersdictionaries.com/ definition/english/wood?q=woods (accessed 29 August 2019).

\section{Information About the Author}

Ilya V. Sergodeev, Candidate of Sciences (Philology), Associate Professor, Department of Philosophy and Linguistics, Snezhinsk Physics and Technology Institute (branch of the National Research Nuclear University “MEPhI”), Komsomolskaya St, 8, 456776 Snezhinsk, Russia, info@mephi.ru, https://orcid.org/0000-0003-1550-4001

\section{Информация об авторе}

Илья Витальевич Сергодеев, кандидат филологических наук, доцент кафедры философии и лингвистики, Снежинский физико-технический институт (филиал Национального исследовательского ядерного университета «МИФИ»), ул. Комсомольская, 8, 456776 г. Снежинск, Россия, info@mephi.ru, https://orcid.org/0000-0003-1550-4001 